Marquette University

e-Publications@Marquette

College of Education Faculty Research and

Publications

Education, College of

$1-1-2006$

Training Community-Based Professionals to Implement an Empirically Supported Parenting Program

Robert A. Fox

Marquette University, robert.fox@marquette.edu

Kathleen M. Duffy

Marquette University

Kathryn M. Keller

Marquette University

Accepted version. Early Child Development and Care, Vol. 176, No. 1 (January 2006): 19-31. DOI. (C) 2006 Taylor \& Francis. Used with permission. 


\title{
Training Community-Based Professionals to Implement an Empirically Supported Parenting Program
}

\author{
Robert A. Fox* \\ Department of Counseling and Educational Psychology \\ School of Education \\ Milwaukee, WI \\ Kathleen M. Duffy \\ Department of Counseling and Educational Psychology \\ School of Education \\ Milwaukee, WI \\ Kathryn M. Keller \\ Department of Counseling and Educational Psychology \\ School of Education \\ Milwaukee, WI
}

Professionals representing 14 community-based organizations were trained at three different sites serving urban and rural families to implement an empirically supported parenting program for families of young children with challenging behaviors. Of the 44 practitioners trained, 23 successfully completed the program, which involved passing a knowledge test and facilitating the entire 10 session program with a family. A total of 28 , primarily 
NOT THE PUBLISHED VERSION; this is the author's final, peer-reviewed manuscript. The published version may be accessed by following the link in the citation at the bottom of the page.

low-income families completed the program. The family outcomes obtained by the facilitators, based on multiple pre-program and post-program measures, were comparable with those reported previously in the literature for facilitators trained in university settings. The challenges inherent in efforts to increase the community's capacity to implement empirically supported programs are addressed.

\section{Introduction}

Empirically supported intervention programs have established a prominent role in research settings (Chambless et al., 1998) with current work directed at delineating principles to assess established treatment programs and to guide the development of new ones (Wampold et al., 2002). Family-strengthening programs represent one emerging area that has incorporated these scientifically based practices (Kumpfer \& Alvarado, 2003). Within this field, significant work has been devoted to establishing effective programs for parents of very young children with challenging behaviors (Webster-Stratton, 1998; Sanders, 1999; Herschell et al., 2002; Fox \& Nicholson, 2003). These programs share a social learning theory framework with an emphasis on the use of behavioral strategies to promote the development of prosocial behaviors and to set effective limits to reduce the challenging behaviors of young children (Sanders \& MarkieDadds, 2002). Normally, parents are seen individually or in groups over the course of 10 or more sessions with a variety of outcomes measures used to demonstrate treatment effectiveness, including selfreport instruments that assess changes in child and parent behaviors and parent stress (Nicholson et al., 2002), marital adjustment, parent anger and depression (Webster-Stratton, 1994), as well as direct observations of parent-child interactions (Eyberg et al., 2001). The effectiveness of these programs has been established across a variety of families including those with conduct disordered and oppositional children (Webster-Stratton, 1984), families living in low-income circumstances (Webster-Stratton, 1998; Nicholson et al., 1999), and cross-culturally (Solis-Camara et al., 2000).

These early intervention programs are important when considering the long-term prognosis for young children with significant behavior problems. During the early years of development, children present their parents with a number of challenging behaviors including tantrums, aggression, non-compliance, overactivity and destructiveness (Achenbach et al., 1987). While many of these 
difficulties represent normal development (Keenan \& Wakschlag, 2000) and will dissipate over time, they do become mild to moderate problems in $10-15 \%$ of young children, with a high probability (50\%) that they will persist through the elementary school years and into early adolescence (Campbell, 1995). Moreover, as young children mature, these early difficulties may increase in severity and lead to psychiatric diagnoses (Campbell et al., 1982).

Despite the availability of number of quality parenting programs to address these early concerns in children, the challenge remains how to best transfer their application to community-based settings. Previous efforts to disseminate empirically supported treatment programs have largely relied on journal articles, book chapters and books, comprehensive treatment manuals and videotapes, and workshops at professional conferences and in community settings (Webster-Stratton, 1994; Eyberg \& Calzada, 1998; Fox \& Nicholson, 2004). What is presently known about the effectiveness of these dissemination efforts is somewhat disheartening. For example, Kumpfer and Alvarado (2003) identified a number of science-based, family-strengthening programs to prevent behavior problems in children and youth. They reported that these programs are being only used by $10 \%$ of community-based professionals, with $25 \%$ of these implementing empirically supported programs with fidelity (Kumpfer, 2002). That is, only two or three out of every 100 professionals are using empirically supported intervention programs as they were intended to be used. Clearly, alternative models are needed to train individuals to competently implement the empirically supported intervention programs with families.

The purpose of this study was to determine the effectiveness of a brief program to train professionals to use an empirically supported intervention program for parents of young children with challenging behaviors. Two questions were posed: (1) Would community-based professionals successfully learn the knowledge and procedures of the intervention program; and (2) Would they effectively deliver the program and achieve results similar to those reported in the literature?

\section{Method}

\section{Training sites}

Three community-based organizations (CBO), offering family services and located within a 250-mile radius in a midwestern state, 
served as the host sites for the facilitator-training program. Two CBOs were situated in small, rural cities (populations < 8000) and one was in a larger, urban area (population 102,000). Host sites were asked to invite participants from among their own staff members and to solicit training participants from other CBOs in their respective areas. A total of $14 \mathrm{CBOs}$ were represented and included community-based professionals from Birth to Three Programs, Head Start, Salvation Army, county public health departments, family resource centers and a number of other family service programs and agencies. Host sites were responsible for providing an appropriate training setting, arranging lunch/ refreshments and maintaining communication with the participants and the leader of the training program (first author). Participants were responsible for a portion of the training fees ( $\$ 75)$ with the remainder covered by grant funds; participants who could not afford the training fees were provided scholarships.

\section{Participants}

Parent facilitators. A total of 44 community-based professionals participated in the facilitator-training program after signing consent forms approved by a university's Institutional Review Board. Position titles included CBO administrator, public health nurse, social worker, parent educator, home visitor, family support specialist, family advocate and teacher. Demographic and other descriptive information regarding the participants are presented in Table 1; the majority of facilitators was over 30 years of age $(84 \%)$ and well educated (Mean $=15.33$ years of education; Standard deviation [SD] $=1.75)$. Diversity was represented in the sample, with over $25 \%$ reporting racial backgrounds other than Caucasian. Most participants had been or were presently married (97\%) and all participants were parents with an average of 2.86 children of their own (SD $=1.44$ ). Participants tended to be mature practitioners who reported a mean of 14.68 years experience $(S D=10.63)$ with children one to five years of age and an average of 9.23 years experience $(S D=8.18)$ working with parents of young children; most had received previous training in parent education (66.7\%). When asked what they hoped to gain from the present facilitator-training program, two major themes emerged in the participants' written responses. The first theme was to improve their general knowledge of parenting and to learn effective tools to use with parents of young children. The second theme was a desire for

Early Child Development and Care, Vol. 176, No. 1 (2006): pg. 19-31. DOI. This article is (C) Taylor \& Francis (Routledge) and permission has been granted for this version to appear in e-Publications@Marquette. Taylor \& Francis (Routledge) does not grant permission for this article to be further copied/distributed or hosted elsewhere without the express permission from Taylor \& Francis (Routledge). 
more specific information about how to better understand and manage difficult behaviors in young children and to reduce physical abuse in families.

Families. A total of 28 parents completed the Parenting Young Children program including the pre-test and post-test measures. An additional seven parents completed the pre-test measure but terminated their involvement in the program prior to completing the post-test measures. Prior to their participation, all parents signed consent forms approved by a university's Institutional Review Board. A portion of the pre-test measure included an intake questionnaire that collected demographic information about the families as well as responses to questions pertaining to their parenting. The average age of the parents completing the program was 30.6 years $(S D=6.67$ ). Most participants were mothers ( $82 \%)$, although four married couples participated in the program together. The parent sample was diverse and included 19 Caucasian, three Latino, two American Indian and two Hmong parents; two parents did not report their race. In the sample, parents reported completing 12.7 years of education (range $=8-16$ ) and $77 \%$ were married. Regarding family income, $41 \%$ reported annual incomes under $\$ 29,000,36 \%$ were between $\$ 30,000$ and $\$ 49,000$, and the remaining $23 \%$ reported earning at least $\$ 50,000$. These families had an average of 2.4 children (range $=1-7$ ) and most (76\%) had not participated in a previous parent education program. Parents who completed the program were compared with those who did not using one-way analyses of variance for continuous variables (parents' age, education, number of children in the home, age of focus child) and chi-square tests for categorical variables (relationship to child, marital status, annual family income, previous parenting class, gender of focus child). The only variable that achieved significance was marital status $[x 2(1)=9.35, p=002]$. Parents who were married were more likely to complete the program (95\%) than parents who were not married (50\%). All of the parents who dropped out of the program were Caucasian; reasons for termination included medical problems in the family, family too busy to continue, one facilitator changed jobs, one family moved or no reason was given.

Parents with more than one child were asked to select a focus child between one and five years of age to concentrate on during the program. The average age of these 24 focus children (four couples had the same focus child) was 3.19 years $(S D=1.52)$. The child for one 
family was eight years old and was accepted in this program because he had developmental disabilities and was functioning at about a fouryear level with behavior problems. Of the sample, $58 \%$ were boys and $42 \%$ were girls and included 14 Caucasian, three Latino, one American Indian, two Hmong and four children of mixed ancestry; $50 \%$ of the parents reported that their children had medical problems in the past including ear infections, asthma, sleep apnea, allergies and reflux problems; three families had sought previous professional help for their children's behavior.

\section{Parent facilitator program}

Facilitators were trained using the Parenting Young Children Program (Fox \& Nicholson, 2003) specifically designed for parents of one-year-old to five-year-old children with challenging behaviors. The first segment of the program focused on how young children influence their parents' thoughts and feelings (e.g. 'When my child talks back to me, I feel angry and worry that my child is becoming disrespectful') and how these internal events may lead to parent reactions (e.g. yelling for the talking back). Parents were taught to gradually adopt a more thoughtful parenting style by teaching them cognitive-behavioral and anger management strategies. Using a familiar stop-and-go traffic light with an imbedded STAR acronym, parents were taught to 'Stop' (red light) and 'Think' (yellow light) about their present thoughts and feelings before responding to their children's behaviors. The goal was to gradually lengthen the parent's response time (e.g. count to 10, take deep breaths) in order to allow sufficient time to consider their present thoughts and feelings and how they might alter them, if necessary, before responding. Parents were given a brightly colored card displaying the STAR strategy to place somewhere in their home to remind them to use the new strategy with their child. Home plans were developed to encourage parents to use this cognitive strategy and report back on its effectiveness during the next session. The second segment of the program focused on helping the parents establish reasonable developmental expectations for their children. Parents were presented with basic information about child development, which was then connected to the STAR cognitive strategy with the addition of the letter A for 'Ask' (yellow light). Parents were taught to Ask themselves about the fairness of their expectations while continuing to Stop and Think about their own thoughts and feelings. If they found that their expectations were not

Early Child Development and Care, Vol. 176, No. 1 (2006): pg. 19-31. DOI. This article is (C) Taylor \& Francis (Routledge) and permission has been granted for this version to appear in e-Publications@Marquette. Taylor \& Francis (Routledge) does not grant permission for this article to be further copied/distributed or hosted elsewhere without the express permission from Taylor \& Francis (Routledge). 
developmentally appropriate, parents were encouraged to alter their expectations before they responded to their child. Home plans encouraged parents to monitor their developmental expectations. Their success with this added strategy was reviewed in the next session. The third and fourth segments of the program emphasized how the parent should 'Respond' (green light) to the child. Both positive nurturing practices and discipline strategies were addressed in these segments. To build on existing family strengths, this segment began by having parents share their own nurturing strategies, which promote their children's development and transmit their family values and culture (e.g. reading, cooking, telling stories, playtime). Existing nurturing skills were then augmented with specific nurturing strategies such as giving good instructions, effective positive reinforcement and planning ahead. Parents were encouraged to positively respond to their child's good behavior through the use of rewards and positive attention. Home plans emphasized the continued use of the STAR acronym with special attention to nurturing. The fourth segment of the program specifically addressed discipline. Parents were taught general guidelines for setting limits on their child's behavior and specific strategies such as redirection, ignoring, natural consequences and time-out. Parents learned age-appropriate techniques to help address their child's challenging behavior, such as the use of redirection for younger children and natural consequences for older children. Specific directions were offered to facilitate the use of these skills most effectively within the unique environments of each of the families (e.g. how to use time-out appropriately in a small apartment with other siblings present). Home plans encouraged parents to implement these new techniques, integrating all of the program's segments with the use of the STAR acronym.

\section{Procedures}

Facilitators. The facilitator training program included two full days of training with each separated by one week to allow participants time to read the material and to begin to assimilate the knowledge and skills covered in the program. Each facilitator received a copy of Parenting young children: a facilitator's guide (Fox \& Nicholson, 2003), which divides the parenting program into 10 sequential sessions. The training program used lecture, discussion, simulations and role-plays to demonstrate the facilitator's role. A training videotape was used to

Early Child Development and Care, Vol. 176, No. 1 (2006): pg. 19-31. DOI. This article is (C) Taylor \& Francis (Routledge) and permission has been granted for this version to appear in e-Publications@Marquette. Taylor \& Francis (Routledge) does not grant permission for this article to be further copied/distributed or hosted elsewhere without the express permission from Taylor \& Francis (Routledge). 
illustrate key program concepts and strategies. Following the two days of formal training, each facilitator was expected to begin to implement the program with a family and complete a pre-program and postprogram evaluation to assess its effectiveness. Two, half-day follow-up consultation sessions were held to review facilitator questions regarding program concepts and strategies, and to address implementation issues that emerged as they facilitated the program with families. Facilitators were encouraged to contact the training instructor by telephone or email if questions arose while facilitating the program with families. Facilitators who met the passing criterion for a 40-item multiple choice test to assess their knowledge of the program's concepts and strategies (80\%) and successfully finished the program with a family, including completing all required pre-program and post-program family evaluation materials, received a facilitator completion certificate.

Families. The Parenting Young Children program was facilitated with families in 10 weekly $1-1.5$-hour sessions. In the present study, most parents were seen individually and no more than two parents participated in the program at the same time; most of these were married couples. Facilitators met at times and in places convenient for the families; typically, the program was offered in the family's home. The facilitator's program guide provides the content and structure for each session. The first session reviews the Parenting Young Children program, includes an initial family assessment and concludes with the development of a family plan. The latter is a guide for how the parent should implement the program goals at home prior to the next session. Each subsequent session begins with a review of the family plan and the success the parent had in implementing it. Next, the previous sessions' content is reviewed and, if necessary, repeated. The pace of the program is dictated by each family's progress. New content is provided for families who are ready for it. Each session concludes with the further development or refinement of the family plan. Families who successfully finish the program received a completion certificate.

\section{Instruments}

Facilitators. Attendance figures were kept for the two days of formal facilitator training and for the two follow-up consultation sessions. A 40-item multiple choice test was developed to assess the facilitator's knowledge of the concepts and strategies covered in the 
Parenting Young Children Program. Coefficient alpha was computed for this test and yielded $r=0.82$, demonstrating good internal consistency for the test items. At the conclusion of the facilitator-training program, facilitators completed a training satisfaction questionnaire that included five items that rated the quality of the two days of formal training (e.g. usefulness of facilitator's guide, training format) on a four-point scale with 1 = needs work, 2 = average, $3=$ good and $4=$ very good, one item that assessed the participants' comfort level in facilitating the parenting program following the two days of training (1 $=$ very uncomfortable to $10=$ very comfortable), two items that assessed the helpfulness of the follow-up consultation sessions using the same four-point scale used previously, and one item that assessed the participants' comfort level in facilitating the parenting program after the consultation sessions on the same 10-point scale used previously.

Families. Each family completed a number of self-report instruments during the first and final sessions with the facilitator. The Parent Behavior Checklist-Short Form (Fox, 1994) is a 32-item rating scale designed to measure the behaviors and expectations of parents of young children between the ages of 1 year and 4 years, 11 months. The Parent Behavior Checklist (PBC) consists of three scales that were empirically derived through factor analyses: Expectations -12 items that measure parents' developmental expectations ('My child should be able to feed him/herself'); Discipline- 10 items that assess parental responses to children's problem behaviors ('I yell at my child for spilling food'); and Nurturing -10 items that measure specific parent behaviors that promote a child's psychological growth ('I read to my child at bedtime'). Items are rated using a four-point frequency scale ( 4 = almost always/ always, 3 = frequently, $2=$ sometimes, and $1=$ almost never/never). The range of meaning of the PBC subscale scores are: Expectations (12-48), with higher scores indicating higher parental expectations and lower scores indicating lower expectations; Discipline (10-40), with higher scores indicating more frequent use of verbal and corporal punishment (e.g. yelling, spanking) and lower scores indicating less frequent use of punishment; and Nurturing (1040), with higher scores suggesting more frequent use of positive nurturing activities. From a representative sample of 1140 mothers, the following internal consistencies using coefficient alphas were reported: Expectations, 0.97; Discipline, 0.91; and Nurturing, 0.82. 
Test-re-test reliabilities for each of the three subscales were:

Expectations, 0.98; Discipline, 0.87; and Nurturing, 0.81. Correlations between the longer 100-item form of the PBC and the shorter form are consistently high across the three subscales: Expectations, 0.97; Discipline, 0.92; and Nurturing, 0.91. The Child Behavior Scale included two scales to separately measure a child's challenging and prosocial behaviors. The challenging behavior scale included nine items (has temper tantrums, doesn't listen, hits or bites); the prosocial behavior scale items included nine items (is affectionate, helps clean up messes, shares toys). Parents rated the frequency of each behavior using a four-point scale ( 4 = almost always/always, 3 = frequently, 2 = sometimes, and $1=$ never/almost never). Separate total scores were computed for the challenging and prosocial scales (possible range of scores $=9-36$ ). Fox and Nicholson (2003) reported coefficient alphas for a maternal sample of 0.80 for the challenging behavior items and 0.91 for the prosocial items.

During the first and final sessions with families, parents were asked to have their focus children present so that the facilitator could directly observe parent-child interactions. Based on this observation and a review of the parents' scores on the self-report items, the facilitator completed an overall quality rating of parent-child relationship using a scale of 0-100 divided into five-point increments with anchors and descriptive paragraphs for each anchor (e.g. 85-100 = exceptional relationship, 45-60 = average relationship, 0-20 = poor relationship). This measure was similar in format to the Children's Global Assessment Scale used to describe a child's functioning (Shaffer et al., 1983).

\section{Results}

\section{Facilitators}

The facilitator-training program included a total of 44 participants. Attendance at the training program was $100 \%$ for day one, $96 \%$ for day two, $93 \%$ for the first follow-up consultation session and $75 \%$ for the second follow-up session. On the 40 item knowledge test, participants obtained an average score of 35.79 (SD $=3.17$, range $=22-40)$; all but three of the participants obtained a passing test score ( $80 \%$ or higher). Participants rated their satisfaction with the training program. For the five items that evaluated the participants' satisfaction for the first two days of training, the average and permission has been granted for this version to appear in e-Publications@Marquette. Taylor \& Francis (Routledge) does not grant permission for this article to be further copied/distributed or hosted elsewhere without the express permission from Taylor \& Francis (Routledge). 
total score was $17.75(S D=1.5$, range $=14-20)$. For the two items that evaluated the participants' satisfaction with the two days of follow-up consultations, the average total score was 7.39 (SD $=0.8$, range $=6-8)$. Participants also rated their comfort level in facilitating the parenting program at the end of the first two days of training and again at the conclusion of the training program using a 10-point scale with 1 = very uncomfortable to $10=$ very comfortable. Participants comfort level scores changed significantly $[t(30)=4.29, p<.001]$ between the end of the two days of training ( mean $=7.19, \mathrm{SD}=2.06$ ) and the conclusion of the training program (mean $=8.36$, SD $=1.66$ ). Of the original 44 participants, 23 were certified for obtaining a passing score on the knowledge test and for facilitating the program with at least one family (52\%); four facilitators completed the program with more than one parent, most of whom were married couples. Facilitators reported that they did not become certified for a variety of reasons including being unable to finish the training program for medical reasons, participating in the training program only to serve as a administrative resource for program staff, not obtaining a passing score on the knowledge test, having families prematurely drop out of the program, and not having sufficient time to implement the program with a family.

\section{Families}

Families finished the program in an average of 10 sessions (range $=7-15$ ) that required an average of 14 weeks to complete (range $=8-32$ ). The pre-test and post-test data for the 28 parents who completed the program are summarized in Table 2. Using paired $t$-tests to compare the pre-test and post-test data, the results showed that parents significantly reduced their use of corporal and verbal punishment as measured by the PBC's. Discipline subscale following the completion of the parenting program $[t(27)=3.22, p=.003]$. The effect size for the significant pre-post change in discipline scores, based on Cohen's (1988) $d$, was 0.53. The PBC Nurturing and Expectations scores did not change significantly. Parents reported a significant decrease in the frequency of their children's challenging behaviors $[t(26)=3.16, p=.004]$ (effect size $=0.63$ ) and a significant increase in prosocial behaviors $[t(26)=3.82, p=.001]$ (effect size $=0.67$ ). In addition, facilitator's ratings of the overall 
quality of the parent-child relationship improved significantly from pre to post testing $[t(24)=8.82, p<.001]$ (effect size $=1.39$ ).

\section{Discussion}

The first question this study addressed was the extent to which community-based professionals would master the knowledge and strategies of an empirically supported parenting program. Despite the fact that the participants ranged in education from high school to college graduates, the majority was successful in acquiring the information presented with an average score of $90 \%$ on the program knowledge test. Facilitators were satisfied with the training format and improved their comfort level in facilitating the parenting program by the conclusion of the training program. However, only 23 of the original 44 community-based professionals (52\%) completed the training program and successfully facilitated the parenting program with at least one family. A number of factors may have contributed to this lower than expected completion rate.

First, community-based programs for families are voluntary and drop-out rates of $50 \%$ have been reported for parenting programs (Nicholson et al., 1999). In the present study, facilitators commonly had to either shorten or extend the 10-week parenting program (up to 32 weeks for one family) and often had to meet at varying times and locations to accommodate their families. Facilitators who already had good working relationships established with families, could be flexible and were highly committed to completing this training program were the most successful. A number of factors have been shown to improve parent participation including: individualized sessions, including both parents in two parent households, meeting the parents at convenient times and places, providing transportation, child care and refreshments, and having financial incentives and certificates for program completion (Kumpfer et al., 2002; Nicholson et al., 2002).

Second, many community-based programs for families do not include formal parent education programs as a core service area. As a result, staff members in these programs often have several different responsibilities as part of their job description. While many may choose or be encouraged to participate in professional training opportunities offered in the community, when they return to their agencies following the training program, they frequently find they do not have sufficient time to implement a quality-parenting program. 
Consequently, if the goal is to increase the community's capacity to provide quality parenting programs, significant time will need to be given to determine which agencies have sufficient infrastructure and resources dedicated to this service area to benefit from a systematic facilitator training program and to maintain a quality parenting program once the training is finished.

Third, even when parent education and support is promoted as an agency service, the responsibility for leading their parenting programs often is delegated to staff members and volunteers from a variety of backgrounds and education levels. Clearly, the job of facilitating an empirically supported parenting program is a not an easy one and requires a full range of clinical knowledge, skills, and experience (Webster-Stratton \& Taylor, 2001). Consequently, carefully recruiting and screening potential participants for facilitator training programs is essential. Presently, we do not know the minimum criteria for successful facilitators. The present study relied on mature individuals with significant experience working with families of young children. Future research should examine the minimum entry criteria needed for successful parent facilitators.

This study also was interested in how well community-based professionals would implement the parenting program. This issue was addressed by comparing outcomes of the present study with comparable studies. Parents in the present study significantly reduced their reported use of corporal and verbal punishment with their young children. The effect size for this result was 0.53 , which compares favorably with previous studies (Brenner et al., 1999; Nicholson et al., 1999). Parents also reported significant improvement in their child's challenging behaviors (effect size $=0.63$ ), which again compares favorably with this previous work. While more research is needed to determine factors that may contribute to effect size in this area (e.g. length of treatment, subject variables such as age, education, marital status and socioeconomic status, number of children in the home, parent support system, the potential influence of social desirability on self-report measures), the effect sizes obtained in the present study would be considered moderate (Cohen, 1988) and suggest that the facilitators were successful in delivering the parenting program.

The present results support the notion that parents can successfully alter the challenging behaviors of their young children. Empirically supported programs that teach effective parenting skills 
(Eyberg \& Calzada, 1998; Webster-Stratton, 1998; Fox \& Nicholson, 2003), may successfully alter the developmental pathway of continued and worsening behavior problems for at least some of these young children as they mature. The knowledge and strategies included in these programs are not complicated to learn; the challenge remains how to best insure that families consistently use them with their young children by having properly trained facilitators available to teach and support them in their efforts.

\section{Notes}

- Corresponding author. Marquette University, Department of Counseling and Educational Psychology, School of Education, Schroeder Complex, Milwaukee, WI 53201-1881, USA. Email: robert.fox@marquette.edu

\section{Acknowledgement}

This research was supported in part by a grant from the Child Abuse Prevention Fund, Milwaukee, WI, USA.

\section{References}

Achenbach, T. M., Edelbrock, C. \& Howell, C. T. (1987) National survey of problems and competencies among four-to sixteen-year olds: parents' reports from normative and clinical samples, Monographs of the Society for Research in Child Development, 56 (Serial No. 225), 1112.

Brenner, V., Nicholson, B. C. \& Fox, R. A. (1999) Evaluation of a communitybased parenting program with the parents of young children, Early Child Development and Care, 148, 1-9.

Campbell, S. B. (1995) Behavior problems in preschool children: a review of recent research, Journal of Child Psychology \& Psychiatry, 36, 113149.

Campbell, S. B., Szumowski, E. K., Weing, L. J., Gluck, D. S. \& Breaux, A. M. (1982) A multidimensional assessment of parent-identified behavior problem toddlers, Journal of Abnormal Child Psychology, 10, 569-592.

Chambless, D. L., Baker, M. J., Baucom, D. H., Beutler, L. E., Calhoun, K. S., Daiuto, A. et al. (1998) Update on empirically validated therapies, II, The Clinical Psychologist, 51, 3-16.

Cohen, J. (1988) Statistical power analysis for the behavioral sciences (2nd edn) (Hillsdale, NJ, Lawrence Erlbaum).

Eyberg, S. M. \& Calzada, E. J. (1998) Parent-child interaction therapy: treatment manual. Unpublished manuscript, University of Florida.

Early Child Development and Care, Vol. 176, No. 1 (2006): pg. 19-31. DOI. This article is (C) Taylor \& Francis (Routledge) and permission has been granted for this version to appear in e-Publications@Marquette. Taylor \& Francis (Routledge) does not grant permission for this article to be further copied/distributed or hosted elsewhere without the express permission from Taylor \& Francis (Routledge). 
Eyberg, S. M., Funderburk, B. W., Hembree-Kigin, T. L., McNeil, C. B., Querido, J. G. \& Hood, K. K. (2001) Parent-child interaction therapy with behavior problem children: one and two year maintenance of treatment effects in the family, Child \& Behavior Therapy, 23(4), 1-20.

Fox, R. A. (1994) Parent Behavior Checklist (Austin, TX, ProEd) (available from corresponding author).

Fox, R. A. \& Nicholson, B. C. (2003) Parenting young children: a facilitator's guide (Longmont, CO, Sopris West).

Fox, R. A. \& Nicholson, B. C. (2004) Young children with behavior problems: an empirically-based prevention program, learning institute presentation at the Meeting of the American Counseling Association, Kansas City, MO, April.

Herschell, A. D., Calzada, E. J., Eyberg, S. M. \& McNeil, C. B. (2002) Parentchild interaction therapy: new directions in research, Cognitive and Behavioral Practice, 9, 9-16.

Keenan, K. \& Wakschlag, L. S. (2000) More than the terrible twos: the nature and severity of behavior problems in clinic-referred preschool children, Journal of Abnormal Child Psychology, 28(1), 33-46.

Kumpfer, K. L. (2002) Prevention of alcohol and drug abuse: what works?, Journal of Substance Abuse, 23, 25-44.

Kumpfer, K. L. \& Alvarado, R. (2003) Family-strengthening approaches for the prevention of youth problem behaviors, American Psychologist, 58, 457-465.

Kumpfer, K. L., Alvarado, R., Smith, P. \& Bellamy, N. (2002) Cultural sensitivity and adaptation in family-based interventions, Prevention Science, 3, 241-246.

Nicholson, B., Anderson, M., Fox, R. \& Brenner, V. (2002) One family at a time: a prevention program for at-risk parents, Journal of Counseling \& Development, 80, 362-371.

Nicholson, B. C., Brenner, V. \& Fox, R. A. (1999) A community-based parenting program with low-income mothers of young children, Families in Society: The Journal of Contemporary Human Services, $80(3), 247-253$.

Sanders, M. R. (1999) Triple P-Positive Parenting Program: towards an empirically validated multilevel parenting and family support strategy for the prevention of behavior and emotional problems in children, Clinical Child and Family Psychology Review, 2(2), 71-90.

Sanders, M. R. \& Markie-Dadds, C. (2002) Behavioral family interventions with children, in: T. Patterson (Ed.) Comprehensive handbook of psychotherapy: cognitive-behavioral approaches (vol. 2) (New York, John Wiley \& Sons).

Early Child Development and Care, Vol. 176, No. 1 (2006): pg. 19-31. DOI. This article is (C) Taylor \& Francis (Routledge) and permission has been granted for this version to appear in e-Publications@Marquette. Taylor \& Francis (Routledge) does not grant permission for this article to be further copied/distributed or hosted elsewhere without the express permission from Taylor \& Francis (Routledge). 
NOT THE PUBLISHED VERSION; this is the author's final, peer-reviewed manuscript. The published version may be accessed by following the link in the citation at the bottom of the page.

Shaffer, D., Gould, M. S., Brasic, J., Ambrosini, P., Fisher, P., Bird, H. \& Aluwahlia, S. (1983) A Children's Global Assessment Scale (CGAS), Archives of General Psychiatry, 40, 1228-1231.

Solis-Camara, P., Fox, R. A. \& Nicholson, B. C. (2000) Parenting young children: comparison of a psychoeducational program in Mexico and the United States, Early Child Development and Care, 163, 115-124.

Wampold, B. E., Lichtenberg, J. W. \& Waehler, C. A. (2002) Principles of empirically supported interventions in counseling psychology, The Counseling Psychologist, 30, 197-217.

Webster-Stratton, C. (1984) Randomized trial of two parent training programs for families with conduct-disordered children, Journal of Consulting and Clinical Psychology, 52(4), 666-678.

Webster-Stratton, C. (1994) Advancing videotape parent training: a comparison study, Journal of Consulting and Clinical Psychology, 62(3), 583-593.

Webster-Stratton, C. (1998) Preventing conduct problems in Head Start children: strengthening parent competencies, Journal of Consulting and Clinical Psychology, 66(5), 715-730.

Webster-Stratton, C. \& Taylor, T. (2001) Nipping early risk factors in the bud: preventing substance abuse, delinquency, and violence in adolescence through interventions targeted at your children ( $0-8$ years), Prevention Science, 2, 165-192.

Early Child Development and Care, Vol. 176, No. 1 (2006): pg. 19-31. DOI. This article is (C) Taylor \& Francis (Routledge) and permission has been granted for this version to appear in e-Publications@Marquette. Taylor \& Francis (Routledge) does not grant permission for this article to be further copied/distributed or hosted elsewhere without the express permission from Taylor \& Francis (Routledge). 
NOT THE PUBLISHED VERSION; this is the author's final, peer-reviewed manuscript. The published version may be accessed by following the link in the citation at the bottom of the page.

\section{Appendix}

\section{Table 1: Characteristics of the participants in the facilitator-training} program

\begin{tabular}{|c|c|c|}
\hline Variable & Number & Percentage \\
\hline \multicolumn{3}{|l|}{ Host Agency } \\
\hline 1 & 14 & 32 \\
\hline 2 & 15 & 34 \\
\hline 3 & 15 & 34 \\
\hline \multicolumn{3}{|l|}{ Age } \\
\hline 20-29 years & 7 & 16 \\
\hline $30-39$ years & 17 & 39 \\
\hline $40-49$ years & 7 & 16 \\
\hline 50 years or older & 13 & 29 \\
\hline \multicolumn{3}{|l|}{ Ethnicity } \\
\hline African-American & 2 & 5 \\
\hline Caucasian & 32 & 74 \\
\hline Latino & 5 & 12 \\
\hline American-Indian & 1 & 2 \\
\hline Asian & 3 & 7 \\
\hline \multicolumn{3}{|l|}{ Education } \\
\hline High school or less & 4 & 10 \\
\hline Post high school & 10 & 24 \\
\hline College graduate & 17 & 40 \\
\hline Post College & 11 & 26 \\
\hline \multicolumn{3}{|l|}{ Marital status } \\
\hline Married & 34 & 81 \\
\hline Not married & 8 & 19 \\
\hline \multicolumn{3}{|l|}{ Number of children } \\
\hline $1-2$ & 19 & 35 \\
\hline $3-4$ & 18 & 33 \\
\hline 5 or more & 5 & 12 \\
\hline
\end{tabular}

Early Child Development and Care, Vol. 176, No. 1 (2006): pg. 19-31. DOI. This article is (C) Taylor \& Francis (Routledge) and permission has been granted for this version to appear in e-Publications@Marquette. Taylor \& Francis (Routledge) does not grant permission for this article to be further copied/distributed or hosted elsewhere without the express permission from Taylor \& Francis (Routledge). 
NOT THE PUBLISHED VERSION; this is the author's final, peer-reviewed manuscript. The published version may be accessed by following the link in the citation at the bottom of the page.

Table 2: Means and standard deviations for each dependent variable at pre-test and post-test

\begin{tabular}{|c|c|c|c|c|}
\hline & \multicolumn{2}{|c|}{ Pre-test } & \multicolumn{2}{|c|}{ Post-test } \\
\hline & Mean & SD & Mean & SD \\
\hline \multicolumn{5}{|l|}{ PBC subscales } \\
\hline Expectations & 31.54 & 9.43 & 32.89 & 8.20 \\
\hline Discipline & 15.25 & 4.40 & $12.89^{*}$ & 3.00 \\
\hline Nurturing & 26.89 & 7,36 & 28.64 & 4.19 \\
\hline \multicolumn{5}{|l|}{ Child Behavior Scale } \\
\hline Challenging Behavior & 19.24 & 3.94 & $16.74^{*}$ & 3.02 \\
\hline Prosocial Behavior & 25.15 & 3.92 & $27.78^{*}$ & 3.89 \\
\hline $\begin{array}{l}\text { Parent-Child Relationship } \\
\text { Scale }\end{array}$ & 55.20 & 12.62 & $72.80^{\circ}$ & 13.00 \\
\hline
\end{tabular}

* Significant change $p<.01$

Early Child Development and Care, Vol. 176, No. 1 (2006): pg. 19-31. DOI. This article is (C) Taylor \& Francis (Routledge) and permission has been granted for this version to appear in e-Publications@Marquette. Taylor \& Francis (Routledge) does not grant permission for this article to be further copied/distributed or hosted elsewhere without the express permission from Taylor \& Francis (Routledge). 